University of Nebraska - Lincoln

DigitalCommons@University of Nebraska - Lincoln

USDA National Wildlife Research Center - Staff Publications
U.S. Department of Agriculture: Animal and Plant Health Inspection Service

2011

\title{
The role of European starlings in the spread of coccidia within concentrated animal feeding operations
}

James C. Carlson

USDA/APHIS/WS National Wildlife Research Center, james.c.carlson@aphis.usda.gov

George M. Linz

USDA/APHIS/WS National Wildlife Research Center, george.m.linz@aphis.usda.gov

Lora R. Ballweber

Colorado State University - Fort Collins

Stacey A. Elmore

Colorado State University - Fort Collins

Susan E. Pettit

USDA-APHIS, Wildlife Services' National Wildlife Research Center

See next page for additional authors

Follow this and additional works at: https://digitalcommons.unl.edu/icwdm_usdanwrc

Carlson, James C.; Linz, George M.; Ballweber, Lora R.; Elmore, Stacey A.; Pettit, Susan E.; and Franklin, Alan B., "The role of European starlings in the spread of coccidia within concentrated animal feeding operations" (2011). USDA National Wildlife Research Center - Staff Publications. 1296.

https://digitalcommons.unl.edu/icwdm_usdanwrc/1296

This Article is brought to you for free and open access by the U.S. Department of Agriculture: Animal and Plant Health Inspection Service at DigitalCommons@University of Nebraska - Lincoln. It has been accepted for inclusion in USDA National Wildlife Research Center - Staff Publications by an authorized administrator of DigitalCommons@University of Nebraska - Lincoln. 
Authors

James C. Carlson, George M. Linz, Lora R. Ballweber, Stacey A. Elmore, Susan E. Pettit, and Alan B. Franklin 


\title{
The role of European starlings in the spread of coccidia within concentrated animal feeding operations
}

\author{
James C. Carlson a,*, George M. Linz ${ }^{\mathrm{b}}$, Lora R. Ballweber ${ }^{\mathrm{c}}$, Stacey A. Elmore ${ }^{\mathrm{c}}$, \\ Susan E. Pettit ${ }^{\mathrm{a}}$, Alan B. Franklin ${ }^{\mathrm{a}}$ \\ a U.S. Department of Agriculture, Animal and Plant Health Inspection Service, Wildlife Services, National Wildlife Research Center, 4101 LaPorte Avenue, Fort \\ Collins, CO 80521, USA \\ b U.S. Department of Agriculture, Animal and Plant Health Inspection Service, Wildlife Services, National Wildlife Research Center, North Dakota Field Office, \\ 2110 Miriam Circle, Suite B, Bismarck, ND 58501-2502, USA \\ c Colorado State University, Department of Microbiology, Immunology and Pathology, College of Veterinary Medicine and Biomedical Sciences, Fort Collins, \\ CO 80523-1619, USA
}

\section{A R T I C L E I N F O}

\section{Article history:}

Received 9 March 2010

Received in revised form 2 February 2011

Accepted 29 March 2011

\section{Keywords:}

Eimeria

European starlings

Peridomestic wildlife

Wildlife disease

Zoonosis

\begin{abstract}
A B S T R A C T
To investigate the relationship between European starlings and bovine coccidiosis we collected samples from European starlings, cattle feed bunks, cattle water troughs, and cattle feces within concentrated animal feeding operations (CAFOs). These samples were screened for coccidia spp. to investigate (i) the prevalence of coccidia in starlings using CAFOs; (ii) if there is a relationship between bovine coccidiosis and starling numbers; (iii) if coccidia contamination of cattle feed and water is related to the number of starlings observed on CAFOs. Coccidia belonging to the genus Eimeria were detected in cattle feces and one water sample but no Eimeria spp. were detected in European starlings or cattle feed. However, many European starling samples were positive for Isospora. Starling use of CAFOs did not appear to be associated with coccidia spp. shedding by cattle and there was no correlation between starling numbers and contamination of cattle feed and water, suggesting that starling do not contribute to the amplification and spread of Eimeria in CAFOs.
\end{abstract}

Published by Elsevier B.V.

\section{Introduction}

Eimeria species are the protozoal causative agents responsible for bovine coccidiosis (Stewart et al., 2008). Coccidiosis is one of the five most economically important diseases to the cattle industry causing an estimated cost of $\$ 100$ million annually within the United States (Kirkpatrick and Selk., 2007). Identifying and mitigating the risk pathways that lead to coccidiosis in concentrated animal feeding operations (CAFOs) may substantially reduce production losses.

European starlings (Sturnus vulgaris) are an invasive bird species that cause seasonal problems for cattle producers.

\footnotetext{
* Corresponding author. Tel.: +1 970266 6127; fax: +1970266 6138 .

E-mail address: James.C.Carlson@aphis.usda.gov (J.C. Carlson).
}

During the winter, starlings will congregate in large foraging flocks and consume abundant and accessible food and water supplies within CAFOs (Glahn et al., 1989). Starlings have also been implicated as sources of and vectors for the pathogens that cause disease in CAFOs (Clark and McLean, 2003; LeJeune et al., 2008). The role of starlings in the spread of coccidia in CAFOs has not been explored; however, at least one species of Eimeria (Eimeria balozeti) has been isolated from starling feces (Yakimoff and Gousseff, 1938).

In this study, we assessed the capacity of European starlings to spread coccidia spp. within and between CAFOs. Specifically, we estimated the prevalence of coccidia spp. in starlings using CAFOs, the prevalence of coccidia spp. within cattle feces and examined whether coccidia contamination of cattle feed and water is related to number of starlings on CAFOs. 


\section{Materials and methods}

Ten CAFOs in Moore, Sherman, and Hansford Counties, TX, USA were selected for sampling based on similarity of feedlot management practices and the presence of starlings. These CAFOs were sampled between January 20 and February 19, 2009.

We estimated starling numbers on CAFOs prior to sample collection at two spatial scales; numbers of starlings on CAFOs (facility level) and numbers of starlings in cattle pens, feed bunks or water troughs within CAFOs (pen level). Facility level estimates were conducted by systematically driving through CAFOs and counting starlings observed in or flying above pens. We were careful to account for bird movement to eliminate duplication of numbers. Pen level estimates consisted of number of starlings observed in feed bunks, water troughs, and cattle pens when feed, water, and fecal samples were collected, respectively.

Feed samples were collected from cattle feed bunks and placed in sterile Whirl-Paks ${ }^{\circledR}$. Water samples were collected from cattle water troughs using sterile $125 \mathrm{ml}$ plastic vials. We collected fresh fecal samples from individual cows. Samples were only collected when an animal was observed defecating to standardize environmental exposure between fecal samples and to eliminate cross contamination from other feces. All fecal samples were stored in sterile Whirl-Paks ${ }^{\circledR}$.

European starlings were collected opportunistically from CAFOs using modified Australian crow traps supplied with fresh feed and water daily. Captured starlings were removed from the traps once a week and euthanized. All starlings were euthanized by cervical dislocation, a method conforming to agency policy as stated in USDA/APHIS/WS Directive 2.505 and approved by the National Wildlife Research Center's (NWRC) Internal Animal Care and Use Committee (IACUC). The distal gastrointestinal tract (proventriculus to the cloaca) was removed and placed in sterile Whirl-Paks ${ }^{\circledR}$. Additionally, one of the starling traps was surrounded by an electric predator fence and the bottom of this trap was reinforced with chicken wire to prevent non-target mammals from burrowing into trap, releasing starlings, and consuming feed. This trap was reinforced so feed and water samples could be collected from a single starling trap each time the birds were euthanized. This process allowed us to collect a small sample of feed and water that was only exposed to starlings.

All samples were shipped overnight on the day of collection to the Colorado State University Veterinary Diagnostic Laboratory (CSUVDL) in Fort Collins, CO. Presence of coccidia in cattle feces was determined using a centrifugal fecal flotation technique (Ballweber et al., 2000) with saturated sugar solution; identification was accomplished using morphologic criteria (Duszynski et al., 1999). The intestinal tracts of the starlings were opened longitudinally; contents were removed and analyzed for presence of coccidia spp. by a saturated sugar centrifugal fecal flotation method. Water samples were concentrated by a 10 min centrifugation process $(1200 \times g)$ to facilitate the isolation of parasites. The supernatant was discarded and the material was examined using centrifugal flotation. Feed samples were processed as soil samples using the method of Kazacos (1983).
Cattle fecal data were analyzed using generalized linear mixed logistic regression (PROC GLIMMIX in SAS 9.2) where test result (presence or absence Eimeria) was the response variable. We developed 8 a priori models to explain the presence of Eimeria shedding by cattle. The explanatory variables assessed in our models consisted of number of starlings at different spatial scales (starlings on facilities, starlings in pens), cattle stocking (cattle on facilities, cattle in pens) and facility management variables (use of anticoccidial feed additives, use of antibiotic feed additives, and cattle pasture fed). The 10 CAFOs were included as random effects. The eighth model included only the intercept (means) and represented a null model. We used a biascorrected version of $\mathrm{AIC}_{c}$ to select the most appropriate model to explain the data (Burnham and Anderson, 2002). Logistic regression models were not constructed for cattle feed and water data because too few positive samples were collected. European starling data was analyzed descriptively, where prevalence of coccidia spp. within European starlings was estimated and comparisons made to the positive cattle feces and water sample.

\section{Results}

Two of the 10 CAFOs sampled had large ( $>10,000$ starlings/day) starling flocks, 4 experienced moderately large (1000-10,000 starlings/day) starlings flocks, and 4 experienced small (<1000 starlings/day) starling flocks.

A total of 533 samples were collected within CAFOs: 218 feed, 173 water, 81 European starling, and 61 cattle fecal samples. Eimeria species were detected in 15\% (9/61) of the cattle fecal samples and $0.6 \%(1 / 173)$ of the water samples. No cattle feed or European starling samples were positive for Eimeria. However, 23\% (19/81) of the GI tracts from European starlings contained Isospora (Table 1).

Based on $\mathrm{AIC}_{c}$ model selection, Eimeria in cattle was best explained by the number of cattle on CAFOs. The number of starlings on CAFOs and the number of starlings in animal pens were not heavily weighted predictors for coccidia contamination of cattle feces (Table 2 ).

A total of 4 different species of Eimeria were detected in cattle feces. Within positive cattle fecal samples $78 \%$ contained Eimeria bovis; 22\% contained Eimeria cylindrica; $11 \%$ were positive for Eimeria auburnensis, and $11 \%$ were positive for Eimeria zurnii (Table 1). Two of the cattle fecal samples contained multiple species of Eimeria: one sample contained $E$. bovis and E. auburnensis the other contained $E$. bovis and E. cylindrica. One water sample from the starling trap was positive for Eimeria but only a few oocysts were isolated making definitive speciation impossible.

\section{Discussion}

Our model selection criteria suggest there is no relationship between starling use of CAFOs and Eimeria shedding by cattle. Eimeria oocysts were not detected in starling GI tracts but many starlings were positive for Isospora spp. This occurred even though starlings were regularly exposed to the cattle shedding Eimeria spp. This information is consistent with previous literature suggesting Eimeria is host specific and unlikely to complete its life 
Table 1

Percentage of positive samples for coccidia species from cattle feces, cattle feed, cattle water, European starling gastrointestinal tracts, food placed in starling traps and water placed in starling traps. All samples were collected in 2009 from 10 CAFOs located in Moore, Sherman, and Hansford Counties, TX.

\begin{tabular}{|c|c|c|c|c|c|c|}
\hline \multirow[t]{2}{*}{ Coccidia species } & \multicolumn{6}{|c|}{ No. samples collected (prevalence, \%) } \\
\hline & Cattle feces & Starling GI tract & Cattle feed & Cattle water & Starling feed & Starling water \\
\hline Eimeria bovis & $61(11.48)$ & $81(0.00)$ & $214(0.00)$ & $169(0.00)$ & $4(0.00)$ & $4(0.00)$ \\
\hline Eimeria cylindrica & $61(3.28)$ & $81(0.00)$ & $214(0.00)$ & $169(0.00)$ & $4(0.00)$ & $4(0.00)$ \\
\hline Eimeria auburnensis & $61(1.64)$ & $81(0.00)$ & $214(0.00)$ & $169(0.00)$ & $4(0.00)$ & $4(0.00)$ \\
\hline Eimeria zurnii & $61(1.64)$ & $81(0.00)$ & $214(0.00)$ & $169(0.00)$ & $4(0.00)$ & $4(0.00)$ \\
\hline Eimeria sp. ${ }^{\mathrm{a}}$ & $61(0.00)$ & $81(0.00)$ & $214(0.00)$ & $169(0.00)$ & $4(0.00)$ & $4(25.00)$ \\
\hline Isospora spp. & $61(0.00)$ & $81(23.46)$ & $214(0.00)$ & $169(0.00)$ & $4(0.00)$ & $4(0.00)$ \\
\hline
\end{tabular}

a Species was not able to be identified by microscopy.

cycle in more than one host (Yun et al., 2000). The only original research documenting the isolation of $E$. balozeti in European starlings came from Yakimoff and Gousseff (1938). Subsequent to this publication we could not find any research that isolated E. balozeti, or any other Eimeria species, from European starlings. The absence of Eimeria in our starling GI tract samples supports the contention of Duszynski et al. (1999) that reports of Eimeria in starlings likely represent pseudoparasites.

One water sample collected during the study was positive for Eimeria. This sample was collected from the water bowl within the starling trap. None of the starling GI tract samples were positive for Eimeria and there was no evidence that other animals could have contaminated the water bowl. We do not believe this single detection is insignificant. The presence of Eimeria in the starling water bowl demonstrates that starlings can mechanically transmit Eimeria oocysts to water sources in CAFOs, even though this was not observed in the samples collected from cattle water troughs. The starling trap was surrounded by an electric predator fence and a mesh bottom prevented burrowing mammals from digging into the trap. Also, water bowls were changed and cleaned daily. The only animals that had access to the water in the trap were starlings. Thus, starlings may be able to mechanically transmit Eimeria within CAFOs even though our data suggests it will not translate to increased contamination of cattle water troughs frequented by starlings.

Our inability to detect coccidia in any cattle water trough raises concerns about the sensitivity of our water sampling. Collection of $125 \mathrm{ml}$ of trough water may have been inadequate for reliable detection of Eimeria oocysts.
The American Society for Testing and Materials (ASTM) established methods for detecting Cryptosporidium oocysts in water. These methods recommend filtering 1001 (or more) of water through a $1.0 \mu \mathrm{m}$ filter cartridge prior to testing (ASTM, 1991). Cryptosporidium oocysts trapped in filters can be eluted and suspended in a smaller volume of water, dramatically increasing the probability of detection (Nieminski et al., 1995). Even though the cattle water troughs sampled held a maximum of 50 gallons (1891), it is possible that the volume was too great for reliable detection without a filtration step, or collection of larger volumes of water. Any future attempts to sample water troughs for coccidia should collect more than $125 \mathrm{ml}$ of water or concentrate water samples in filters prior to conducting flotation tests. In conclusion, because of the small sample size these results should only be viewed as a preliminary assessment of the role starlings play in the spread or amplification of coccidia spp. in CAFOs. Future work should be conducted to better assess the capacity of starling to mechanically transmit coccidia oocysts in CAFOs.

\section{Acknowledgements}

Funding for this project was provided by USDA/APHIS/WS/NWRC. We would like to thank Texas Wildlife Services and the Texas Cattle Feeders Association for their assistance in obtaining industry cooperation. Without their commitment to research we would not have been able to conduct this study. Lastly we would like to thank Ron Sinclair for his technical expertise and innovative solutions for measuring European starling disease transmission in CAFOs.

Table 2

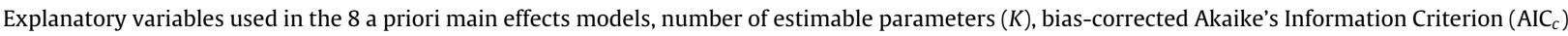
and Akaike weight $\left(w_{i}\right)$ for the logistic regression models explaining the probability of coccidia spp. contamination in cattle feces. All data was collected within 10 concentrated animal feeding operations located in Moore, Sherman, and Hansford Counties, TX, 2009.

\begin{tabular}{lllll}
\hline Model structure & $K^{\mathrm{a}}$ & $-2 \log L$ & AIC $_{c}$ \\
\hline$\beta_{0}+\beta_{1}$ (number of cattle on site) & 3 & 43.150 & 49.571 \\
$\beta_{0}+\beta_{1}$ (number of cattle in pens) & 3 & 47.920 & 54.341 \\
$\beta_{0}$ (intercept-only) & 2 & 50.560 & 54.767 \\
$\beta_{0}+\beta_{1}$ (number of starlings in pens) & 3 & 48.590 & 55.011 \\
$\beta_{0}+\beta_{1}$ (number of starlings on site) & 3 & 49.560 & 55.981 \\
$\beta_{0}+\beta_{1}$ (antibiotics in feed) & 3 & 50.370 & 56.791 \\
$\beta_{0}+\beta_{1}$ (anti-coccidial in feed) & 3 & 50.500 & 5.008 \\
$\beta_{0}+\beta_{1}$ (cattle pasture fed) & 3 & 50.520 & 0.005 \\
\hline
\end{tabular}

\footnotetext{
a Number of estimable parameters based on the number of logistic regression coefficients plus an estimated covariance from the random effect of CAFOs.
} 


\section{References}

American Society for Testing and Materials, 1991. Test methods for Giardia cysts and Cryptosporidium oocysts in low-turbidity water by a fluorescent antibody procedure (ASTM P229). In: Annual Book of ASTM Standards 11.01, Philadelphia (withdrawn 1995).

Ballweber, L.R., Evans, R.R., Siefker, C., Johnson, E.G., Rowland, W.K., Zimmerman, G.L., Thompson, L., Walstrom, D.J., Skogerboe, T.L., Brake, A.C., Karle, V.K., 2000. The effectiveness of doramectin pour-on in the control of gastrointestinal nematode infections in cow-calf herds. Vet. Parasitol. 90, 93-102.

Burnham, K.P., Anderson, D.R., 2002. Model Selection and Multimodel Inference: A Practical Information-Theoretical Approach. Second edition, Springer-Verlag, New York, New York, 488 pp.

Clark, L., McLean, R.G., 2003. A review of pathogens of agricultural and human health interest found in blackbirds. In: Linz, G.M. (Ed.), Proceedings of Symposium on Management of North American Blackbirds, 103-108. USDA/APHIS /WS, National Wildlife Research Center, Fort Collins, CO.

Duszynski, D.W., Upton, S.J., Couch, L., 1999. Coccidia of Passeriformes (Eimeria spp.). Available from: http://biology.unm.edu/biology/ coccidia/passer.html (accessed 03.12.09.).
Glahn, J.F., Mason, J.R., Woods, D.R., 1989. Dimethyl anthranilate as a bird repellent in livestock feed. Wildl. Soc. Bull. 17, 313-320.

Kazacos, K.R., 1983. Improved method for recovering ascarid and other helminth eggs from soil associated with epizootics and during survey studies. Am. J. Vet. Res. 44, 896-900.

Kirkpatrick, J.G., Selk. G., 2007. Coccidiosis in cattle. Oklahoma Cooperative Extension Service fact sheet, F-9129: http://pods.dasnr.okstate.edu/ docushare/dsweb/Get/Rendition-5577/unknown (accessed 03.12.09.).

LeJeune, J., Homan, H.J., Linz, G.M., Pearl, D.L., 2008. Role of the European starling in the transmission of E. coli 0157 on dairy farms. In: Timms, R.M., Madon, M.B. (Eds.), Proc. Vertebr. Pest Conf. 23, 31-34.

Nieminski, E.C., Schaefer III, F.W., Ongerth, J.E., 1995. Comparison of two methods for detection of Giardia cysts and Cryptosporidium oocysts in water. Appl. Environ. Microbiol. 61, 1714-1719.

Stewart, I.D., Smith, R.P., Ellis-Iverson, J., 2008. Eimeria species in cattle on farms in England and Wales. Vet. Rec. 162, 482-483.

Yakimoff, W.L., Gousseff, W.F., 1938. Les coccidie du pinson (Fringilla coelebs L.). Ann. Soc. Belge Med. Trop. 18, 523-525.

Yun, C.H., Lillehoj, H.S., Lillehoj, E.P., 2000. Intestinal immune response to coccidiosis. Dev. Comp. Immunol. 24, 303-324. 